The purchase of any new equipment for use in language learning centers requires careful investigation by the buyer. Experience has shown that the lowest price should not be the sole criteria for purchase. It is also true that paying the highest price does not always mean trouble--free operation. The purchase process should, therefore, consist of several carefully planned steps:

1. Determine which functions are absolutely necessary for your planned use of the equipment.

2. If possible, visit a number of dealers who sell the type of equipment you are interested in. Compare the prices and the functions offered.

3. Attend trade shows so that you can see a wide variety of equipment.

4. Read magazines such as Consumers Reports, Video Review, etc. Although designed for the home market, the comments and testing procedure offer lab directors a good starting point for learning how to evaluate equipment.

5. Educational Products Information Exchange (EPIE) Reports are another good source of information. They give detailed test reports of various types of educational equipment.

6. Check with other schools concerning the manufacturer's reputation for fulfilling terms of the warranty and his willingness and ability to supply spare parts.

7. Include the following items in the equipment purchase order:

a. A request for the service manual.

b. A request for a list of other companies who can supply generic spare parts.

c. A training program for the operation and repair of the equipment including a preventive maintenance program.

\title{
Selection of Equipment
}

It is possible to avoid over-buying or under-buying by listing those features essential to your program. All too often schools have bought 'systems' rather than 'products' and have ended up with packages that were not properly used. A one-page advertisement distributed by Marron Carrels listed some important buying considerations:

1. What are your needs?

2. Does this product meet today's needs and tomorrow's?

3. What is the history of the manufacturer? What warranties exist? Are specifications substantiated?

4. What kind of service/technical assistance can be expected?

5. Who uses this item and what are their recommendations?

6. What is the life-span of this item under normal and under heavy programs? 


\section{Maintenance Program}

Assuming that the appropriate system or piece of equipment was purchased, it is important that funds be established for maintaining the operations at the most cost-effective level. Maintenance is a long-term continuing effort that includes cleaning, calibration, and measurement of video and audio equipment to ensure reliability and performance. A routine service $\log$ on all equipment will identify recurring problems and help document claims should major problems arise. Debris, rubber remains, tape particles, and heavy dust are clues to aid the technician in his diagnosis of malfunctions. All controls should be checked for static, dirt and dust buildup and all cables and connectors need to be cleaned and tested. Students can be trained to handle some tasks, but a well-trained technician/ engineer must do a follow-up for a complete maintenance program to be effective.

In budgeting for maintenance the largest portion, almost $60 \%$ of the annual budget will be labor. About $25 \%$ is spent on parts and tools. Each school must decide whether it is more cost-effective to have an in-house technician or to use a local repair facility. Some of the factors to be considered about the latter are:

a. What is the cost of each service call?

b. What is the cost if the product is taken by the staff to the repair facility?

c. Are loan units or replacement units available?

d. What is the normal time frame for repair?

e. How long can the school do without the equipment?

f. Will the manufacturer repair the unit?

Diagnosing the problem requires common sense and testing. Reports from repair centers indicate that almost $55 \%$ of the problems could have been avoided by reading the instruction booklet.

Some suggestions for keeping "down-time" to a minimum include these seven ideas (2):

1. "Burn In" the Equipment--Most failures occur within the first 72 hours of operation, therefore, use the new equipment extensively before the warranty period expires.

2. Read the manual-A careful reading of the manual may prevent unnecessary trips to the repair facility and may give you good tips for prevention of malfunctions.

3. Reduce static electricity--This is essential for computers and for any type of electronic equipment that contains CPUs.

4. Avoid heat buildup--Avoid exposure to the sun, inadequately ventilated cabinets/rooms, or other sources of heat buildup.

5. Work switches and controls periodically to shake loose dust and oxide accumulation on the contacts.

6. Use dust covers and vacuum or blow out dust from the insides of equipment. 
7. Check wiring forproper grounding and make sure that wiring connections from one piece of equipment to another are out of traffic patterns.

\section{Equipment and Tools Required by a Typical Learning Center}

(NOTE: In the following listing some recommendations are made regarding specific products. These recommendations are the result of the authors' experiences and do not constitute an endorsement by the IALL nor is there any intention to exclude other brands).

\section{Electronic Equipment}

F.E.T. Volt Ohm Meter (VOM)--used for measuring DC voltages, continuity, resistance, and semi-conductors.

Vacuum Tube Volt Meter (VTVM)--used for measuring noise, operating 1 level, and frequency response.

Oscillator--produces (at a minimum) tones in the $20 \mathrm{~Hz}$ to $20 \mathrm{kHz}$ region with less than .1\% distortion or, preferably, a unit which will produce sine waves between $5 \mathrm{~Hz}$ and $200 \mathrm{kHz}$, and give an output level of at lease $+25 \mathrm{dBm}$ (square waves and pulses as well as sine waves).

Oscilloscope--provides for two vertical inputs with flat frequency response from DC to $30 \mathrm{MHz}$ (minimum), triggered sweep with a trce that does not dissappear at the higher sweep rates, external trigger input, trigger source selection and indication--needs a $10 x$ probe. This type of unit will cost in excess of $\$ 500$.

Vectorscope

\section{Optional Test Equipment}

Lavell VTVM--A measuring instrument from Great Britain that measures beyond the average ranges.

Triggered Oscilloscope--For observing the initial rise of the bias and erase waveforms so as to find what causes "punch-in" and "punch-out" pops on tape machines (Hewlett-Packard, Hitachi, Leader, Non-Linear Systems, and Tektronix).

Acoustilog Impulser

Urei Soni-Pulse

Fluke 8060A

Function Generators

Distortion Analyzer

Real-Time Analysis

SPL Measurement

Frequency Response Plotter and Warble Tone Systems

Reverb Time Analysis

Spectrum Analyzer 
Tension Gauges

Screwdrivers:

1. Philips in three versions, the common American types in sizes 0,1 , and 2; the 'pozi-drive' in sizes 1 and 2 for equipment made in Great Britain; the 'vessel' type that fits Japanese screws that conform to ISO standards in sizes 0 and 2 (crosspoint).

2. The standard straight edge in a variety of types and sizes.

Soldering Equipment:

1. The common soldering iron with temperature control in the 700-800 range and a good treated tip. The tip should also be isolated from the $A C$ line that the iron is plugged into. Some recommended makes and/or models are:

a. Weller--W60 for portable use and the WtCP line for bench work.

b. Oryx--any model

c. Ungar--Ungarmatic $50 t, 9000$ or 9200 series

d. Hex a con-therm-0-trac series

e. Edsyn--loner series

f. Therm-o-trac--temp-controlled stations

2. Solder sucker--The best of these are the metal barrel type with either a teflon or nylon tip. The tip material is important because the tip must be placed directly on the molten solder connection for proper removal. Recommended are the Paladin--PA 1700 or the Erem-DP-D1 or T2.

3. Solder Pick--when soldering, there are two different types of picks needed: 1) This type cleans out solder-filled holes and bridges while holding small parts in place as they are being soldered (this one must be made of stainless steel and strong enough to stand heat and mechanical stress); 2) An orange wood with pointed ends for clearning holes while not leaching the heat away from the connection.

4. Solder--Use rosin core solder (not acid core) and, preferably, one identified with the label "WRAP3" from either Ersyn or Kester Multi-core. Recommended reading is Solders and Soldering by Howard Manko.

\section{Wrenches}

1. A complete selection of "spin-tights" in the American configuration with a complete selection of end and box wrenches for both standards plus a crescent wrench (Snap-on or Xcellite).

2. Allen wrenches

3. The three Studer hex wrenches and head fastener.

4. The Otari set of very small wrenches. 


\section{Pliers}

1. A pair of 3/12" standard long nose, a pair of long bent long nose, and a pair of extended thin long nose; other options are the chain link, electrician's, lead forming, channel lock, and vise grip. Brands are Erem, Vaco, Barco, Diamalloy, Xcellite, Klein, Utica, Lindstrom, and Vigor.

\section{Nut Drivers}

1. $3 / 16^{\prime \prime}, 5^{\prime} 16^{\prime \prime}, 1 / 4^{\prime \prime}$, and $11 / 31^{\prime \prime}$.

Cutters

Hacksaw

Files

1.6" bastard and mill, fine pitch, and a set of jewelry files.

Drills

1. An electric hand drill and a set of bits, fractional sizes from $1 / 16$ to $1 / 2$ inch and numbered sets 0-60.

\section{Pliers}

1. Strippers--Xcellite model 100, Klein model 100, and Erem 410HL

2. Diagonal cutters--Xcellite $73 \mathrm{cg}$ or Scelite $95 \mathrm{cg}$ flush cutters.

3. Flush-cutting tip diagonal cutters--Erem 90E1 tip dykes

\section{Demagnetizers}

1. Standard types are available from Nortronics, Radio Shack, and TDK.

2. For erasure of large quanitities of audio cassette tapes a belt type eraser is recommended.

\section{SUPPLIES}

1. Alignment tapes for video and audio

2. Test tapes and films

3. Optional test charts for video and cameras

4. Head cleaners Audio-Video

5. Rubber cleaners--Teac's RC-2

6. Canner air--Dust Away or PRB

7. Cotton swabs--avoid those with plastic stick

8. Isopropyl alcohol

9. Carbon tetrachloride

10. Lubricants

11. Freezil for tracing heat failures

12. Contact cleaners and tuner baths (G.C. Electronics)

13. Anti-static spray

14. Degreasers--Chemtronics Formula 111

15. Silicone heat sink compound 
16. Various adhesive compounds

17. Extension cords and adapters

18. Patch cords

19. Fuses

20. Spare pilot lamps

21. Projector bulbs

22. Tape repair kits and splicing blocks (Robbings)

23. Equipment covers

24. A supply of electronic spare parts, spare boards or modules.

The following list of suggested readings may assist you in the repair process:

Anderton, Craig L. "Choosing the Right Equipment." AV Video June 1984. ----.. "Dealing With Down Time." AV Video November 1985.

-----, "Understanding Frequency Response, Part 1." AV Video February 1984.

----.. "understanding Mixers." AV Video July 1984.

Bogossian, Benjamin. "Maintenance Schedule for Video and Audio Equipment." EITV February 1986.

Colgan, Ron. "Careful Evaluation Leads to Right Camera." AV Video January 1986.

Hanks, Greg. "Budgeting for the Cost of Maintenance." MIX 10, ii (1986). ----. "Do-it-Yourself Maintenance." MIX 9, x (1985).

Kelly, Nancy D. "The Scoop on Scopes." EITV October 1985.

McClain, Bebe, "A Primer on How to Use a Waveform Monitor." EITV 13, ix (1984).

McClain, Bebe and Harvey Waldman. "Tests and Measurements." EITV 14 (1985).

Montgomery, William W. "Measuring a TV System." EITV 12 (1985). 


\section{BOOKS}

Audio-Visual Equipment Directory NAVA, 3150 Spring Street, Fairfax, VA 22030 , annually, $\$ 30.00$, (discount to AECT members)

Belt, Forest $\mathrm{H}$. How to Interpret Waveforms. Blue Ridge Summit, PA: Tab Books.

Buchsbaum, Walter $\mathrm{H}$. Complete TV Servicing Handbook. Reston, VA: Prentice-Hall, Inc., 1982.

Folger, Walter. Radio, TV, and Sound System Diagnosis and Repair. Reston, VA: Prentice-Hall Co., 1980.

Goodman, Robert L. How to Troubleshoot and Repair Electronic Circuits. Tab Books, Inc., 1981.

Grolle, Carl G. Electronic Workshop Manual and Guide. Parker Publishing Co., 1977.

----. Electronics Technician's Handbook of Time-Savers \& Shortcuts. Parker Publishing Company, Inc., 1974.

Hallmark, Clayton. Understanding and Using the Oscilloscope. Blue Ridge Summit, PA: Tab Books.

Link, John. Video Cassette Recorder: Operation and Servicing. Englewood Cliffs, NJ: Prentice-Hall, 1983.

Roth, Charles. Use of the Dual-Trace Oscilloscope. Englewood Cliffs, NJ: Prentice-Hall, 1982.

Schmid, William T. Media Center Management. New York, NY: Communication Arts Books, Hastings House Publishers.

Utz, Peter. The complete Home Video Book. Englewood Cliffs, NJ: Prentice Hall.

\section{Footnotes}

1. Hanks, Greg MIX $9, \times(1985): 82-90$.

2. Anderton, Craig. AV Video November 1985, pp. 20-21. 